\title{
AERODYNAMIC PERFORMANCE OF THE UNDERBODY AND WINGS OF AN OPEN-WHEEL RACE CAR
}

\begin{abstract}
Summary
Basic aerodynamic characteristics of a generic open-wheel race car equipped with various aerodynamic devices are studied. The focus is on the influence of car underbody design and the front and rear wings on aerodynamic forces experienced by the car. Computational simulations are carried out assuming the steady viscous fluid flow and using the Reynolds-averaged-Navier-Stokes equations and the standard shear stress transport (SST) $k-\omega$ turbulence model. The lift force in the configuration with a flat car underbody (without a rear diffuser at the trailing edge of the car underbody) and without the wings is positive (undesirable upforce), while a negative lift force (favourable downforce) is obtained in all configurations with aerodynamic devices (underbody rear diffuser, front wing, rear wing). The aerodynamic devices create an increased, undesirable drag force in comparison with the configuration without the aerodynamic devices. The downforce and the drag force are similar when wings consisting of two and three elements are used. This indicates that, for the same overall chord and wind incidence angle, the number of wing elements is not a very important factor influencing the aerodynamic loads experienced by this type of open-wheel race car with a similar front and rear wing layout. The optimal configurations with respect to the lift-to-drag ratio are those with the rear diffuser and wings in place. In the configuration with threeelement wings, streamlines in the region of the rear wing are analysed both computationally and experimentally using the tuft flow technique. Good agreement between the computational and limited experimental results regarding streamlines is achieved. However, this would need to be further analysed quantitatively in order to fully validate the developed computational model.
\end{abstract}

Key words: $\quad$ Race car aerodynamics, car underbody and wings, computational simulations, field experiments.

\section{Introduction}

Race cars can experience extreme aerodynamic loads during the race due to various devices designed to optimize the race car aerodynamics, e.g. rear diffuser at the trailing edge of the car underbody as well as the front and rear wings on the car body [1]. The main focus is on enhancing the aerodynamic downforce that generally improves the car traction and stability, while simultaneously trying to avoid a considerable increase in the drag force as it 
increases fuel consumption and adversely affects the car performance [2]. While favourable effects of various devices on the race car aerodynamics are generally known, further work is still required to fully elucidate characteristics of multi-element wings and car underbody in order to improve their aerodynamic characteristics.

Aerodynamic properties of passenger and race cars are commonly studied experimentally in wind tunnels, but significant efforts are made in the computational fluid dynamics in order to improve its reliability and accuracy for that purpose [3]. Therefore, the development of car aerodynamics nowadays commonly combines wind-tunnel experiments, field measurements and computational simulations.

Reference [4] points out the importance of improving the cornering ability of race cars. Aerodynamic devices have been developed for the Formula SAE car, with a special focus on the rear diffuser, and the front and rear wings, as reported in [5]. The flow field around the Formula SAE car is studied in [6] as well, indicating a considerable influence of the front and rear wings on the car aerodynamics. Reducing the race car frontal area and streamlining its body can significantly reduce fuel consumption, e.g. [7]. The drag force can be reduced using passive and active flow control devices, which stimulate the flow to separate closer to the trailing edge of the car [8]. Flow around the tyres proved to be an important issue with the open-wheel cars [9] as the tyres account for up to $40 \%$ of the total drag force [10]. In general, the open-wheel cars have the wheels outside the main body of the car (e.g. Formula 1 race car), while the wheels of the closed-wheel cars are embedded in the main car body (e.g. standard passenger car). The drag force due to the front tyres can be reduced by the aerodynamic optimization of the front wing [11]. It is considered that reduced ground clearance (distance from the road to the car underbody surface) increases the front wing downforce and decreases the drag force of the front tyres [12-13]. Vortex generators on the bottom surface of the front wing have a positive effect as they postpone the flow separation so that it occurs closer to the trailing edge of the wing [14]. A complex interplay between the rear wing and the underbody rear diffuser proved to be an important issue [15].

Aerodynamic devices are effective in improving the passenger car dynamics as well, e.g. [16-17]. Increase in the rear diffuser angle with respect to the ground surface can decrease an adverse upforce [18]. Reduction in fuel consumption can be achieved by optimizing the rear diffuser shape [19].

The present study focuses on basic effects of the race car underbody and the front and rear wings on aerodynamic forces experienced by a simplified, generic open-wheel race car. These parts of the car are aerodynamically designed in order to increase the favourable downforce without considerably increasing the adverse drag force. The obtained computational results serve as an insight about the influence of various aerodynamic devices on aerodynamic forces experienced by an open-wheel race car.

\section{Computational setup}

The studied race car is the FSB RT-04 Arctos Formula Student car of the University of Zagreb manufactured in the 2013/2014 academic year. Lateral cornering forces produced by the tyres of this race car type are commonly greater than $1.5 \mathrm{G}$. Various aerodynamic devices are used to improve the cornering ability. At the car speed of $100 \mathrm{~km} / \mathrm{h}$, the aerodynamic downforce is approximately $80 \%$ of car weight, while the drag consumes around $20 \%$ of the engine power. The computational model is simplified by introducing a flow which is symmetrical with respect to the vertical symmetry plane of the car. Thus, the computational simulation is carried out with only one (left-hand) side of the car, while the results are assumed to be identical on the right-hand side of the car, Fig. 1. 


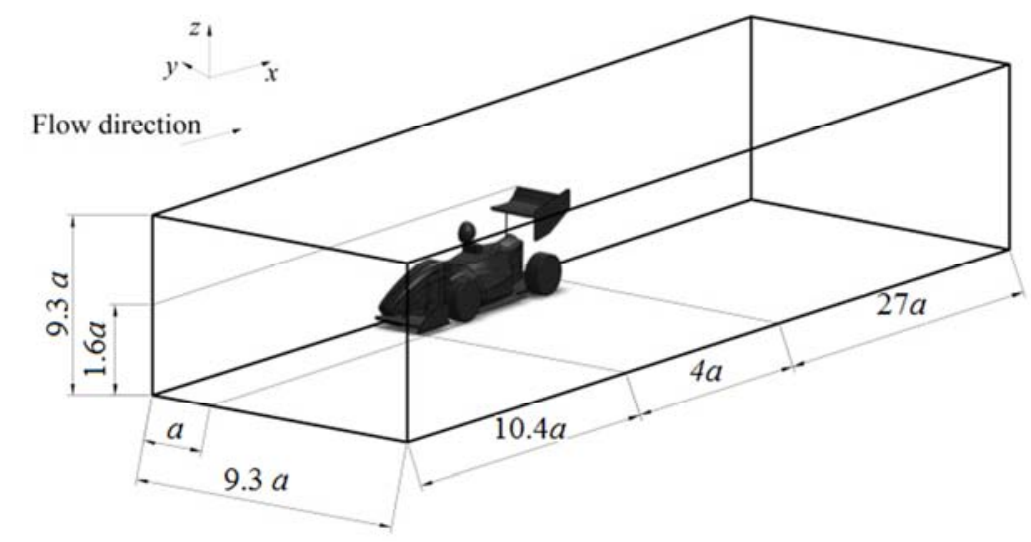

Fig. 1 Schematic isometric view of the computational domain and the car model; dimensions are given in millimetres, $a=750 \mathrm{~mm}$

Fine details of the car geometry, such as suspension parts, wheel internals and engine components are not modelled, see [4], since they are considered not to significantly influence the aerodynamic force coefficients and the modelling of these details considerably increases the complexity of the meshing procedure and the time required to perform the calculations. In all simulations, there is a driver model in the race car model.

Four different configurations are studied: A is the car model with a flat underbody; B is the car model with the rear diffuser at the trailing edge of the car underbody; $\mathrm{C}$ is the car model with the rear diffuser at the trailing edge of the car underbody and front and rear wings consisting of two elements; D is the car with the rear diffuser at the trailing edge of the car underbody and with front and rear wings consisting of three elements, Table 1.

Table 1 Details of the studied configurations

\begin{tabular}{|c|c|c|c|}
\hline Configuration & Underbody & Front wing & Rear wing \\
\hline A & Flat & - & - \\
\hline B & Rear diffuser & - & - \\
\hline C & Rear diffuser & Two elements (2EL) & Two elements (2EL) \\
\hline D & Rear diffuser & Three elements (3EL) & Three elements (3EL) \\
\hline
\end{tabular}

The car models of configurations $\mathrm{C}$ and $\mathrm{D}$ are presented in Fig. 2.

\section{a) Configuration $\mathrm{C}$}

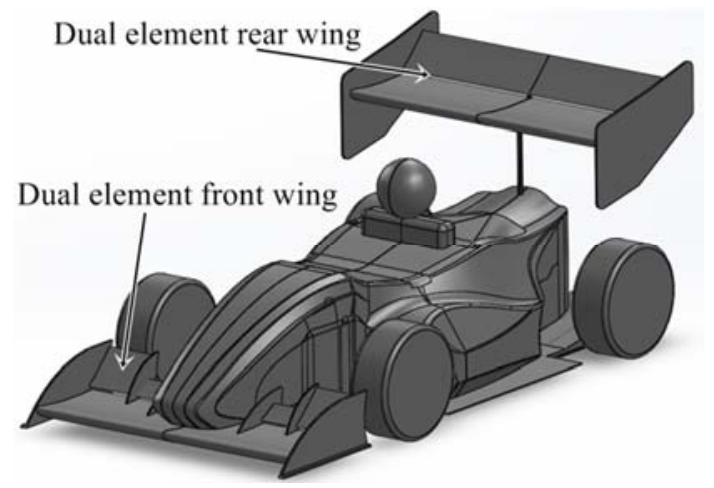

b) Configuration D

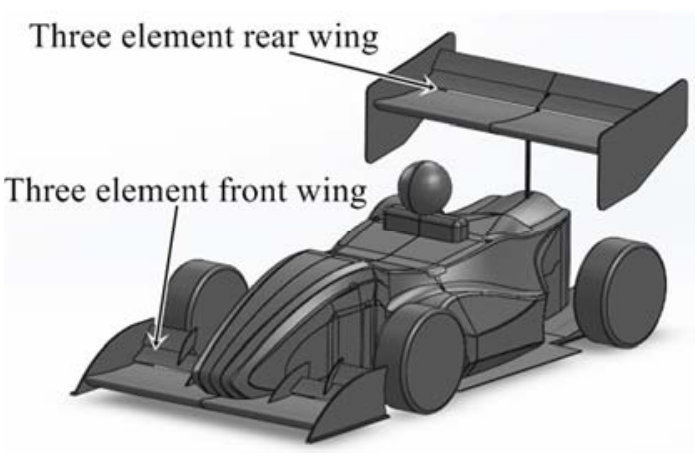

Fig. 2 Geometrical model of the studied race car, configurations $\mathrm{C}$ and D 
The critical blockage factor of the model in the computational domain is commonly accepted to be $6 \%$ [20]. Hence, dimensions of the computational domain for all configurations analysed in this study are designed to satisfy this requirement. For example, the car blockage of the computational domain in configurations $\mathrm{A}$ and $\mathrm{B}$ is $0.87 \%$ and $1.2 \%$ in configurations C and D.

Geometrical discretization is performed in the Gambit 2.4 commercial software using several blocks of unstructured tetrahedral cells; the mesh is finer close to the car, where large gradients in the observed physical values are expected, Fig. 3.

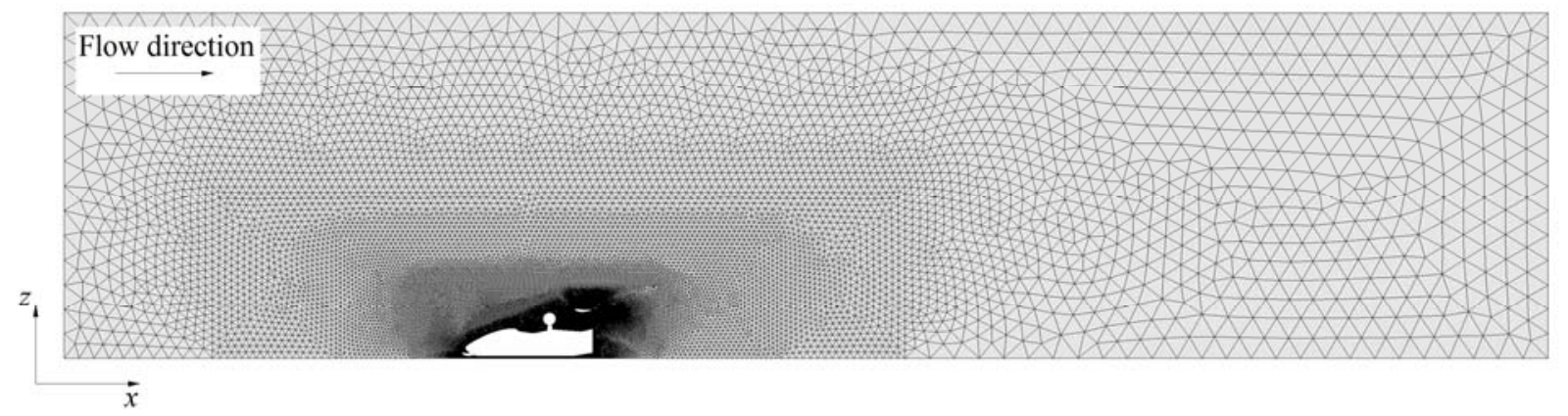

Fig. 3 Geometrical discretization of the computational domain in the car symmetry plane, configuration D

Given that the car geometry with aerodynamic devices is relatively complex, the tetrahedral mesh is used close to the car surface as well, Figs. 4 and 5. Thus, very high grid density in the first layers close to the car surface is applied to allow for precise calculations of flow characteristics. This approach generally increases the computational time but it generally requires less effort than geometrical discretization. In general, the computational accuracy obtained using the same number of control volumes is slightly lower when tetrahedral mesh is used than in the case of prism layers, e.g. [21], whereas the adopted approach is considered to be satisfactory for the present study, e.g. [22]. The height of the first volume node near the car body is determined based on the recommended $y^{+}$values of 30 - 60 that allow for precise modelling of flow characteristics close to the car surface, in agreement with [23].
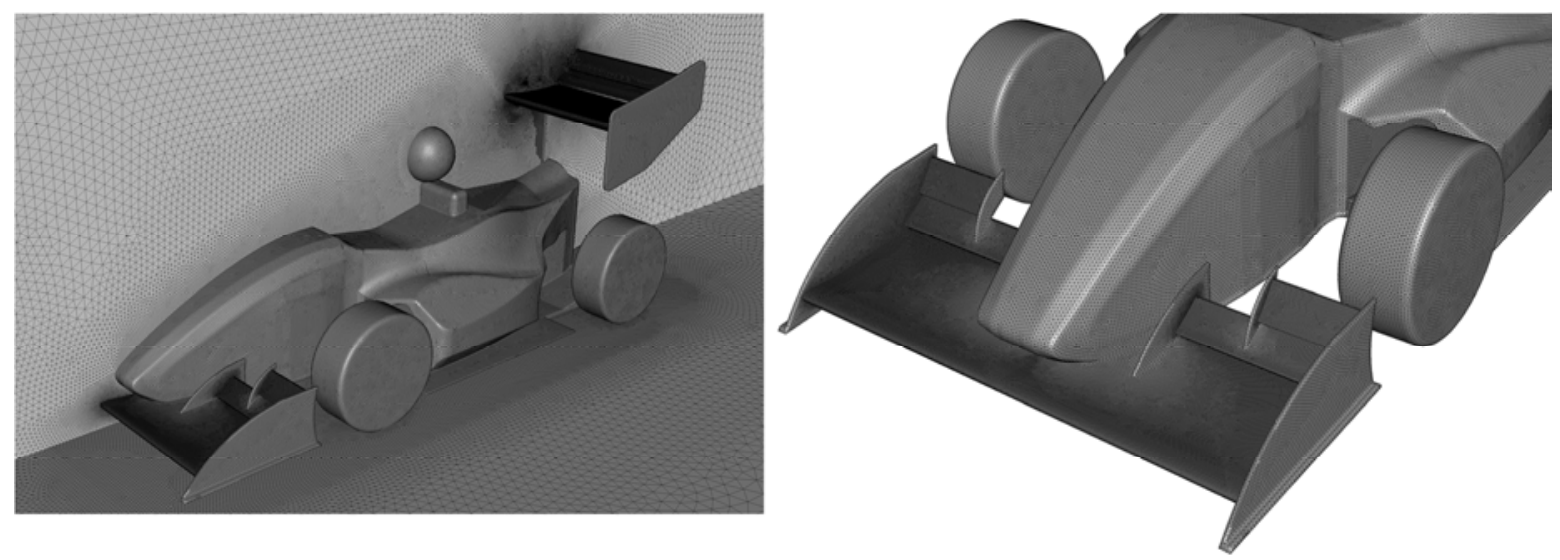

Fig. 4 Geometrical discretization of the car body, configuration D 

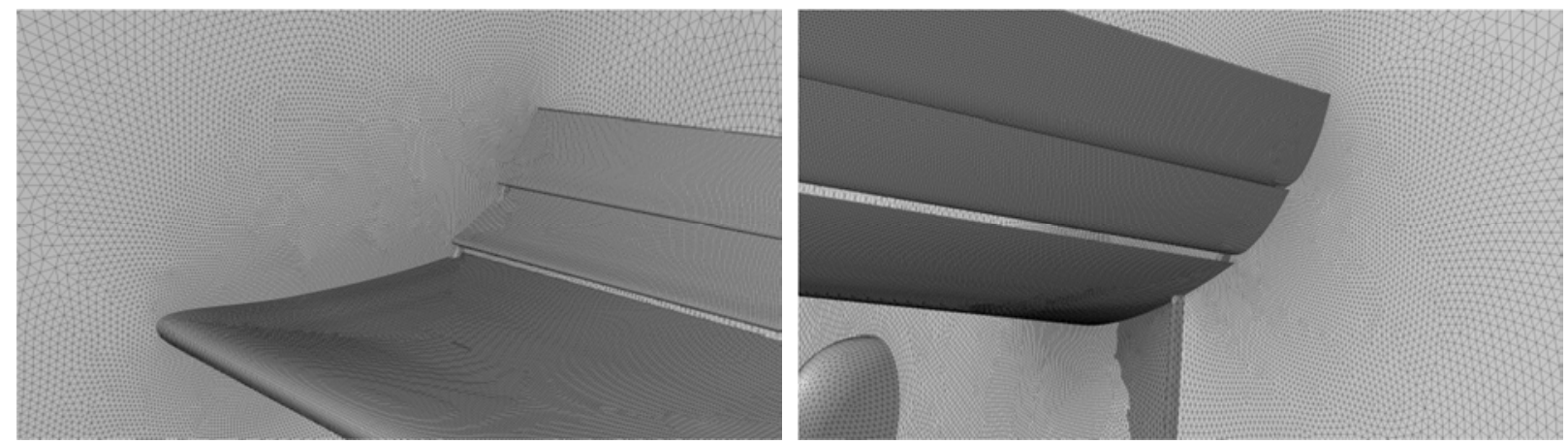

Fig. 5 Geometrical discretization close to the car, configuration D

The number of control cells of the tested configurations is: $1.1 \times 10^{6}$ cells for configuration A, $2 \times 10^{6}$ cells for configuration $\mathrm{B}, 4.9 \times 10^{6}$ cells for $\mathrm{C}$, and $4.6 \times 10^{6}$ cells for D. Preliminary grid independence tests proved that the studied physical values do not change considerably when $y^{+}$values in a range $60-300$ are used.

As the rotation of the wheels considerably influences the airflow around the open-wheel cars, e.g. [10], wheel rotation is simulated in the present study as well. The bottom surface of the computational domain is simulated without developing the boundary layer, e.g. [24]. These conditions, corresponding to those existing on the road, are achieved by: a) making the bottom wall surface of the computational domain move in the main flow direction at the same velocity as the flow does, b) rotating the wheels as a multiple reference frame (MRF) zone, and c) a non-moving car model. The symmetrical boundary condition is applied to the symmetry, top and lateral planes of the computational domain. A static wall with no-slip boundary condition is applied to the car body and to the front and rear wings. The intersection of the tyre and the road is modelled in a way that the road intersects the tyre at the height $0.02 D$ measured from the bottom of the tyre, where $D$ is the diameter of the tyre.

The aim of this study is to analyse the time-averaged aerodynamic forces acting on a standard race car, whereas the transient aerodynamic effects are not studied. The computational setup was developed using the Fluent v15.0 commercial software for stationary incompressible turbulent viscous flow. The computations were performed using the Reynolds-averaged-Navier-Stokes (RANS) equations for the stationary incompressible turbulent viscous flow and the Boussinesq approximation:

a) Continuity equation

$$
\frac{\partial \bar{v}_{j}}{\partial x_{j}}=0
$$

b) Momentum equation

$$
\frac{\partial}{\partial x_{j}}\left(\bar{v}_{j} \bar{v}_{i}\right)=-\frac{\partial \bar{p}}{\partial x_{i}}+\frac{\partial}{\partial x_{j}}\left[\mu\left(\frac{\partial \bar{v}_{i}}{\partial x_{j}}+\frac{\partial \bar{v}_{j}}{\partial x_{i}}\right)+\mu_{t}\left(\frac{\partial \bar{v}_{i}}{\partial x_{j}}+\frac{\partial \bar{v}_{j}}{\partial x_{i}}\right)-\frac{2}{3} \rho \bar{k} \delta_{i j}\right] .
$$

Components of the averaged flow velocity are denoted as $\bar{v}_{i}$, while $x_{i}$ are the coordinates, $\rho$ is the density, $\bar{p}$ is the averaged pressure, $\mu$ is the dynamic viscosity, $\mu_{t}$ is the turbulence viscosity, $\bar{k}$ is the averaged turbulence kinetic energy $\bar{k}=\frac{\overline{v_{i}{ }^{\prime} v_{i}{ }^{\prime}}}{2}$. Since the flow separation is expected to occur in the car wake, the standard $k-\omega$ turbulence model with shear stress transport (SST) is used together with the RANS model as this turbulence 
model has previously proved to be particularly suitable for studying car aerodynamics, e.g. [13]. More details on the SST $k-\omega$ turbulence model can be found in [25].

The calculated physical quantities are uniform at the inlet of the computational domain. Based on the average cornering velocity of the studied race car type, e.g. [4], the undisturbed velocity at the inlet of the computational domain in all simulations is set to be $14 \mathrm{~m} / \mathrm{s}$. The turbulence kinetic energy and the dissipation of turbulence kinetic energy at the inlet are determined based on the selected turbulence intensity of $0.1 \%$ and turbulence integral length scale of $0.01 \mathrm{~m}$, which both correspond to the low-turbulent flow. This is generally in agreement with real race track conditions, where a race car is moving through quiescent air and experiences low freestream turbulence. Approximation of physical quantities on the surfaces of control volumes is performed using the values of physical quantities in the centres of control volumes. An iterative procedure in all configurations started using the first order upwind numerical scheme and finished using the second order upwind numerical scheme. More details on these numerical schemes are provided in [26]. Calculations are performed until the residuals of all studied physical quantities are less than $10^{-5}$, which was usually accomplished after 1000 iterations and 6-10 hours of computations using an 8-core processor. The lift and drag coefficients proved to asymptotically reach the convergence. The pressure coefficients $C p$ are calculated as

$$
C_{p}=\frac{p-p_{\infty}}{\frac{1}{2} \rho v_{\infty}^{2}},
$$

where $p$ is the pressure, $p_{\infty}$ is the pressure of undisturbed inlet flow, $v_{\infty}$ is the undisturbed inlet velocity. The drag and lift forces are analysed based on the calculated aerodynamic coefficients, respectively,

$$
\begin{aligned}
& C_{D}=\frac{F_{D}}{\frac{1}{2} \rho v_{\infty}^{2} A_{D}}, \\
& C_{L}=\frac{F_{L}}{\frac{1}{2} \rho v_{\infty}^{2} A_{L}} .
\end{aligned}
$$

$C_{D}$ is the drag coefficient, $C_{L}$ is the lift coefficient, $F_{D}$ and $F_{L}$ are the aerodynamic drag and lift forces calculated for one half of the car model, $A_{D}$ and $A_{L}$ are the reference areas of the drag and lift force coefficients, respectively. The reference area of both aerodynamic coefficients is the frontal area of one half of the car as observed from the main wind direction. If the aerodynamic forces were calculated for the entire car model (not just one half), it is expected that the non-dimensional aerodynamic coefficients (calculated using the pressure distribution on the entire car surface and the entire car frontal area) would be the same as in the present approach due to symmetrical flow conditions on the right-hand and left-hand sides of the car. For configurations $\mathrm{A}$ and $\mathrm{B}, A_{D}=A_{L}=0.43 \mathrm{~m}^{2}$ and, $A_{D}=A_{L}=0.6 \mathrm{~m}^{2}$ for $\mathrm{C}$ and D. Field experiments are carried out for configuration $\mathrm{D}$ of the studied race car in order to partially validate the obtained computational results. The geometrical scale of the race car model is 1:1. A camera with sampling frequency of $50 \mathrm{~Hz}$ is placed on the surface of the end plate directly attached to the rear wing, Fig. 6. Streamlines of the flow at the bottom surface of the rear wing are observed using the tuft flow visualization technique. This is the simplest and most affordable experimental technique available for the flow visualization as it enables the analysis of basic flow phenomena. 


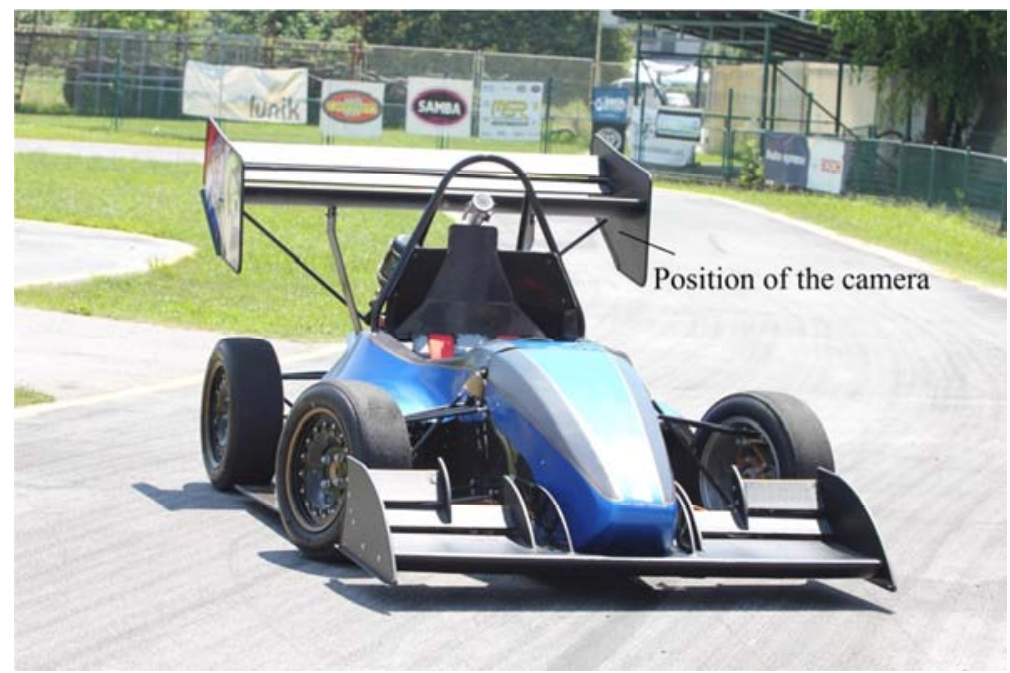

Fig. 6 Prototype model of the studied race car, configuration D

\section{Results and discussion}

Preliminary 2D computational simulations of the car symmetry plane are performed to investigate effects of the rear diffuser length and slope on underbody flow characteristics. The goal is to determine the rear diffuser angle that will yield the maximal downforce-todrag ratio experienced by the race car. Based on the performed $2 \mathrm{D}$ calculations of the velocity field and streamlines, a $600 \mathrm{~mm}$ long rear diffuser with a slope of $9.5^{\circ}$ proved to be favourable for the studied race car as the adverse flow separation in the rear diffuser is not observed in this configuration. As for the 3D model, the flow characteristics of the rear diffuser are expected to change slightly due to the lateral suction of the air from the sides of the car into the diffuser, which may decrease the functionality of the diffuser, e.g. [1]. Even though the 2D simulations are not completely accurate when determining the optimal diffuser angle due to the previously described phenomenon, they serve as a good tool for the estimation of optimal slope angle of the rear diffuser, while some modifications are necessary when designing the 3D model presented in Fig. 7. In 3D simulations, the width of the rear diffuser is $b=1000 \mathrm{~mm}$.

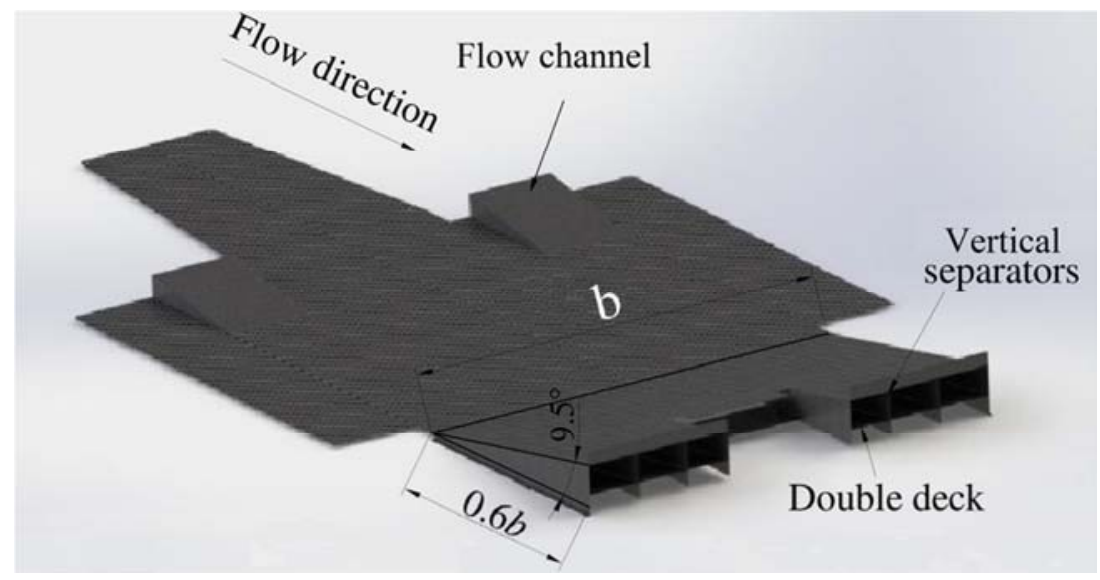

Fig. 7 Car underbody with the rear diffuser in place, $b=1000 \mathrm{~mm}$

In order to reduce the flow turbulence and lateral suction of air along the edge of the underbody, a double deck, vertical separators, and lowered side pods are installed in the diffuser, e.g. [15]. 
As the geometrical model with the selected rear diffuser geometry is developed, 3D computational simulations are performed for configurations $\mathrm{A}$ and $\mathrm{B}$. The velocity field around the car in the symmetry plane of configurations A and B is presented in Fig. 8.

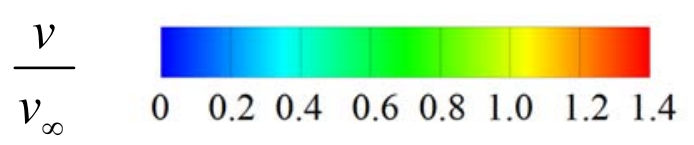

a) Configuration $\mathrm{A}$

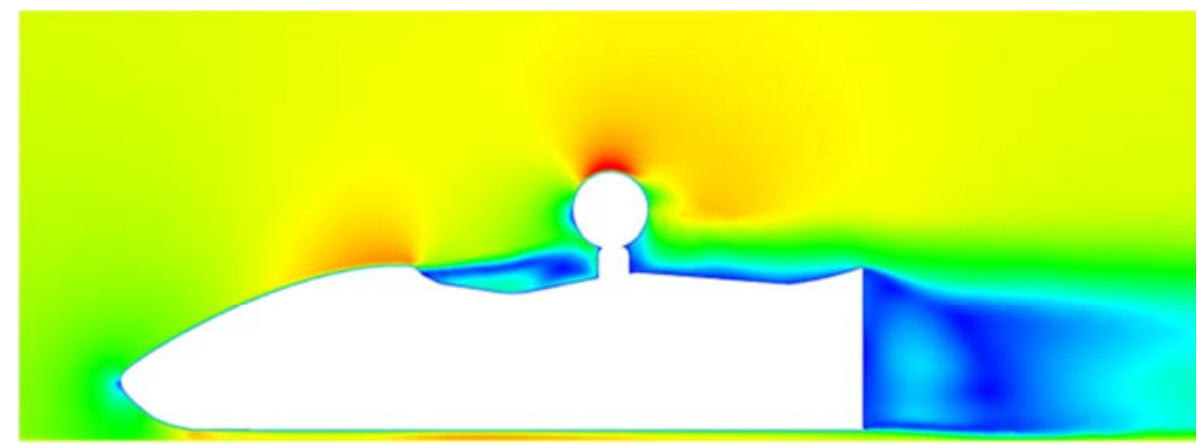

b) Configuration $\mathrm{B}$

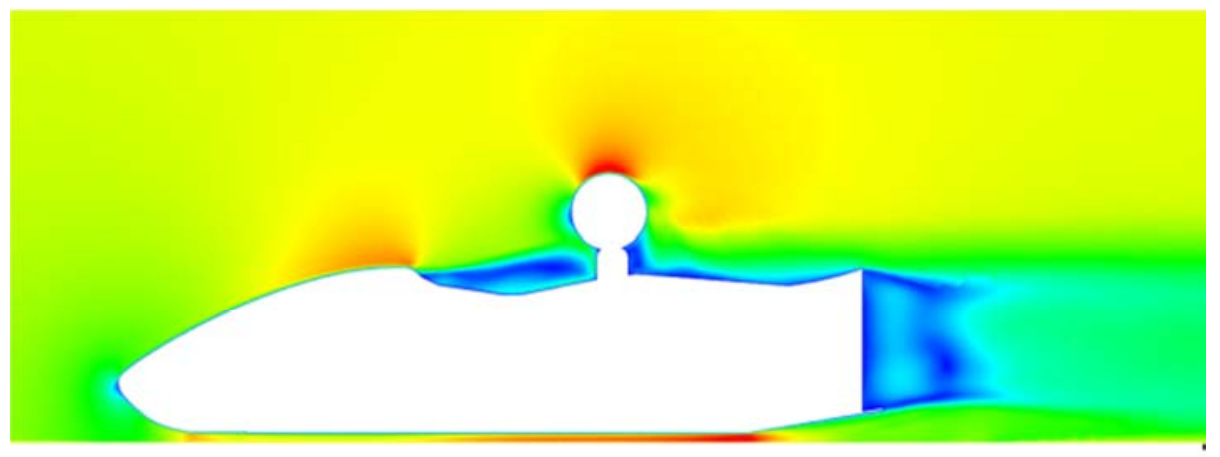

Fig. 8 Velocity field in the car symmetry plane of configurations A and B

While the velocity field in the symmetry plane above the car is similar in both setups, an increased flow velocity under the car and windward from the rear diffuser is observed in configuration B. In addition, the wake downstream of the car is considerably shorter in model $\mathrm{B}$ than in model A.

The distribution of pressure coefficients $\left(C_{p}\right)$ over the car underbody surface in configurations A and B is shown in Fig. 9.

$$
C_{p}
$$

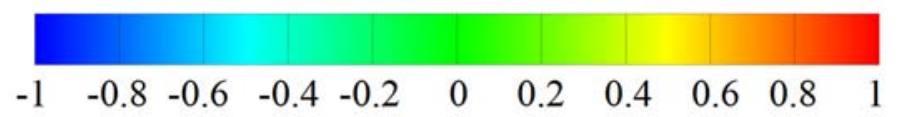

a) Configuration $\mathrm{A}$

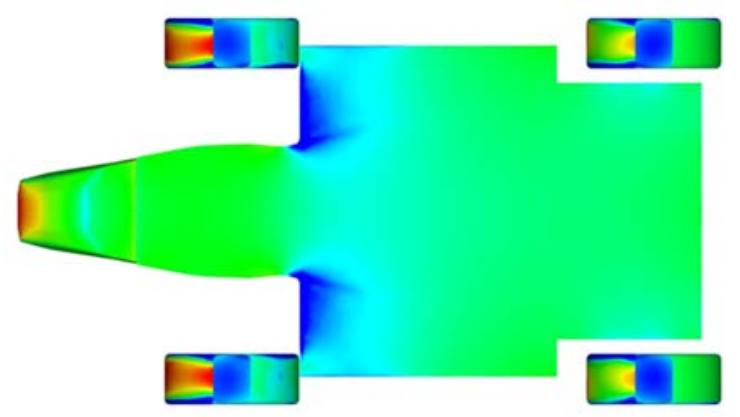

b) Configuration $\mathrm{B}$

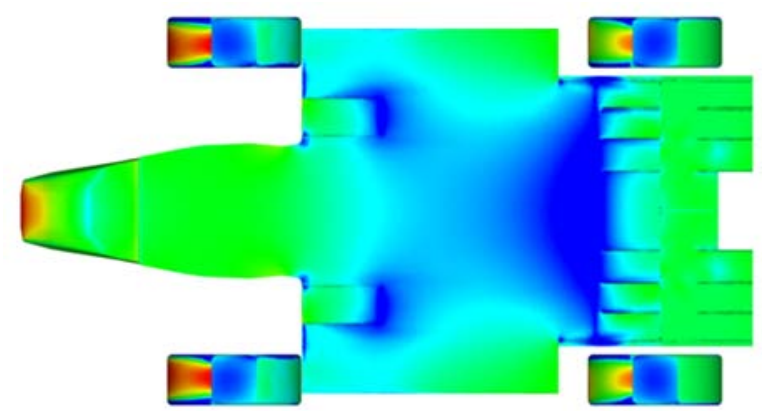

Fig. 9 Distribution of pressure coefficient $C_{p}$ over the car underbody surface in configurations A and B 
Negative pressure coefficients $C_{p}$ on the car underbody are obtained in both configurations, probably due to the ground effect, which is in agreement with [27]. Areas with the negative $C_{p}$ on the car underbody are more pronounced when the rear diffuser is in place. The greatest negative $C_{p}$ around - 1 is observed upstream of the rear diffuser; while $C_{p}$ gradually increases (becomes less negative) through the diffuser. The beneficial effect of the rear diffuser on the car aerodynamics is clearly shown by the distribution of negative $C_{p}$ values distribution on the car underbody upstream of the diffuser, as the rear diffuser contributes to enhancing the favourable downforce experienced by the race car. These results indicate that configuration $\mathrm{B}$ (with a rear diffuser in place) can be considered as aerodynamically more suitable for the race car than configuration A (without arear diffuser). An interesting phenomenon is stronger suction at the car underbody immediately downstream of the front wheels, which is a result of flow channels installed in the underbody with the rear diffuser, as presented in Fig. 7.

As the beneficial effect of the rear diffuser is determined, the analysis focuses on the front and rear wings. Preliminary 2D computations are carried out on the flow around the NACA8415 and NACA9318 airfoils to determine favourable incidence angles of the flow with respect to the airfoils. The goal is to determine the geometry of front and rear wings that will yield the maximal downforce-to-drag ratio. As significantly higher values of downforce without a considerable increase in the drag force have been previously achieved using the wings that consist of several elements [1], 2D computational simulations are also carried out in our study in order to determine the wind incidence angle and the position of the airfoils, i.e. to define configurations $\mathrm{C}$ and $\mathrm{D}$. Based on the performed simulations, the favourable setup of airfoils in configurations $C$ and $D$ are presented in Fig. 10. In both configurations, the slot gap between the first two upstream elements is $0.0225 c$, where $c$ is the chord of the wing main element, and the overlap is $0.0425 \mathrm{c}$. In configuration $\mathrm{D}$, the slot gap between the second and the third element is $0.0125 c$, and the overlap is $0.0225 c$.

a) Configuration $\mathrm{C}$

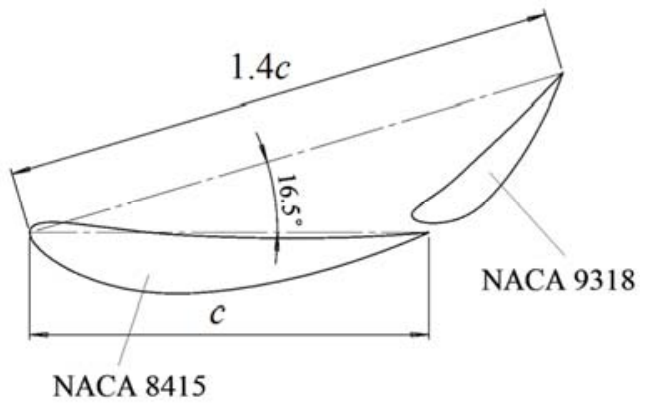

b) Configuration D

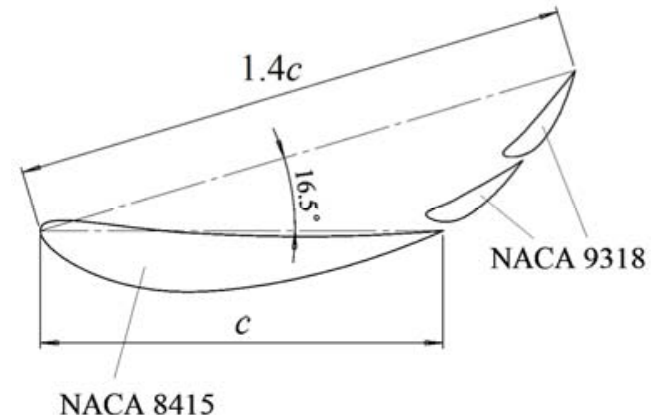

Fig. 10 Front and rear wing geometry of configurations $C$ and D, $c=400 \mathrm{~mm}$

As the front and the rear wing geometry are determined for configurations $\mathrm{C}$ and $\mathrm{D}$, in which the airfoils are not attached to the car, further 3D simulations are performed with the $3 \mathrm{D}$ wings attached to the car model. The $C_{p}$ distribution obtained at the front part of the car in configurations $\mathrm{C}$ and $\mathrm{D}$ is presented in Fig. 11. 
$C_{p}$

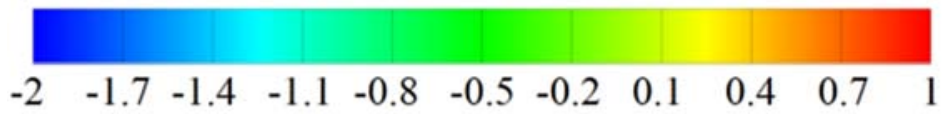

a) Configuration $\mathrm{C}$
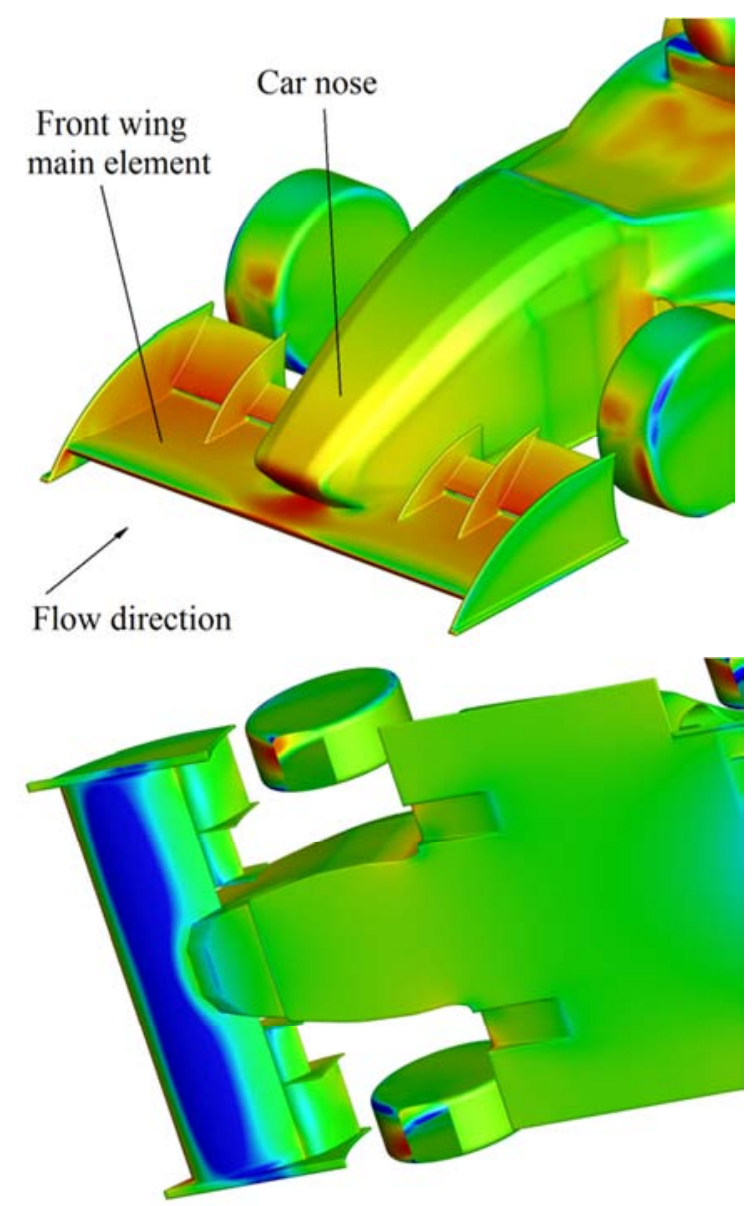

b) Configuration D
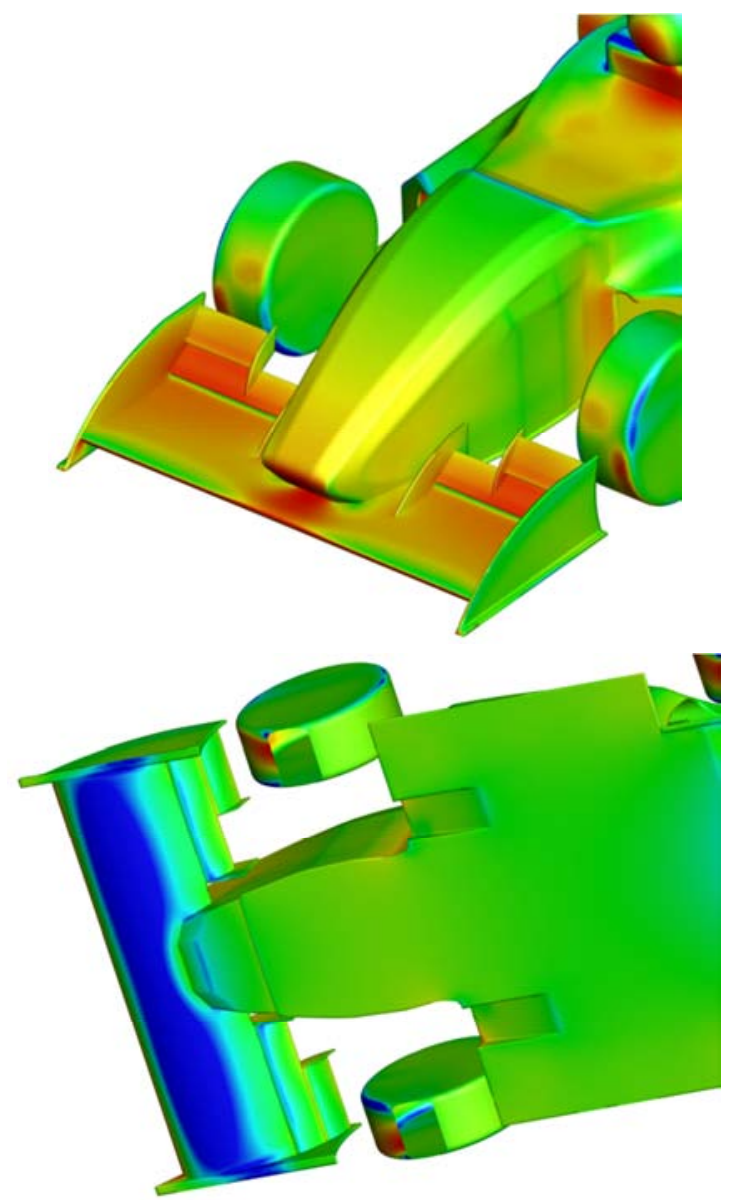

Fig. 11 Distribution of pressure coefficients $\left(C_{p}\right)$ over the front part of the car in configurations $C$ and $D$

Pressure coefficients $C_{p}$ are positive on the top surface of the front wing and are slightly larger in configuration D. They are negative on the bottom surface of the front wing, with strong suction observed at the main element of the front wing in configurations $\mathrm{C}$ and $\mathrm{D}$ due to the ground effect. Comparable results are obtained in [1], where it is reported that the ground clearance of 0.1-0.3 of the wing chord length can substantially increase the downforce created by the wing. High $C_{p}$ values under the car body nose, as well as on the top surface of the front wing main element can be observed in both configurations.

With the front wing flaps (the second and third wing elements when observed in the flow direction), a positive $C_{p}$ is present on the top surface, while the negative $C_{p}$ on the bottom surface is more pronounced close to the leading edge. This is due to the convergent shape of the gap between the main wing element and the flaps as the air accelerates passing through the gap. This additionally allows for the flow separation control on the bottom surface of the flaps, Fig. 12. 


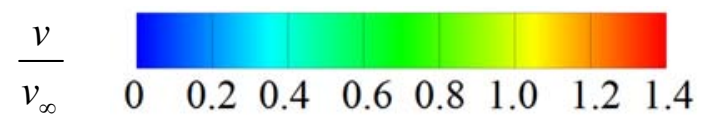

a) Configuration $\mathrm{C}$

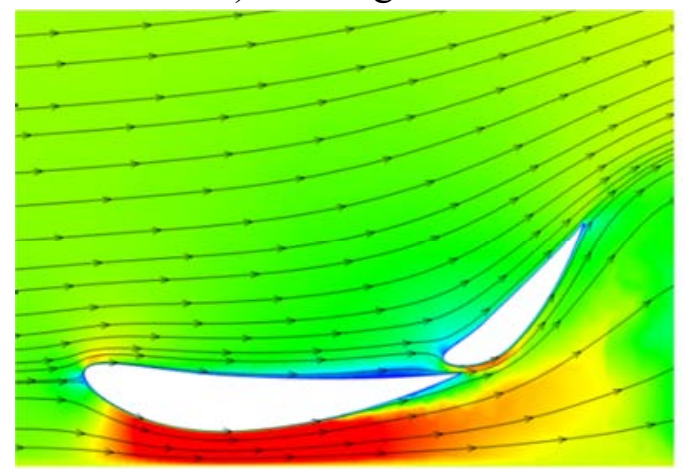

b) Configuration D

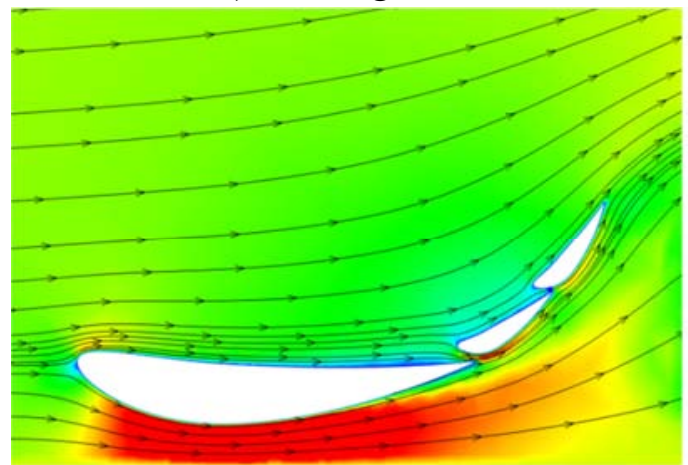

Fig. 12 Velocity field and streamlines close to the front wing presented in the cross-sectional plane at $y=0.5 \mathrm{~m}$ $(y=0 \mathrm{~m}$ is the vertical symmetry plane of the car)

Streamlines close to the front wing elements indicate that the flow separation is not present in configurations $\mathrm{C}$ and $\mathrm{D}$. These results show that the front wing in these configurations performs nearly in the same way with respect to aerodynamic forces and flow characteristics.

Further analysis focuses on the flow characteristics and aerodynamic loads in configurations $\mathrm{C}$ and $\mathrm{D}$ with respect to the rear wing design. Fig. 13 shows the $C_{p}$ distribution at the rear part of the car.

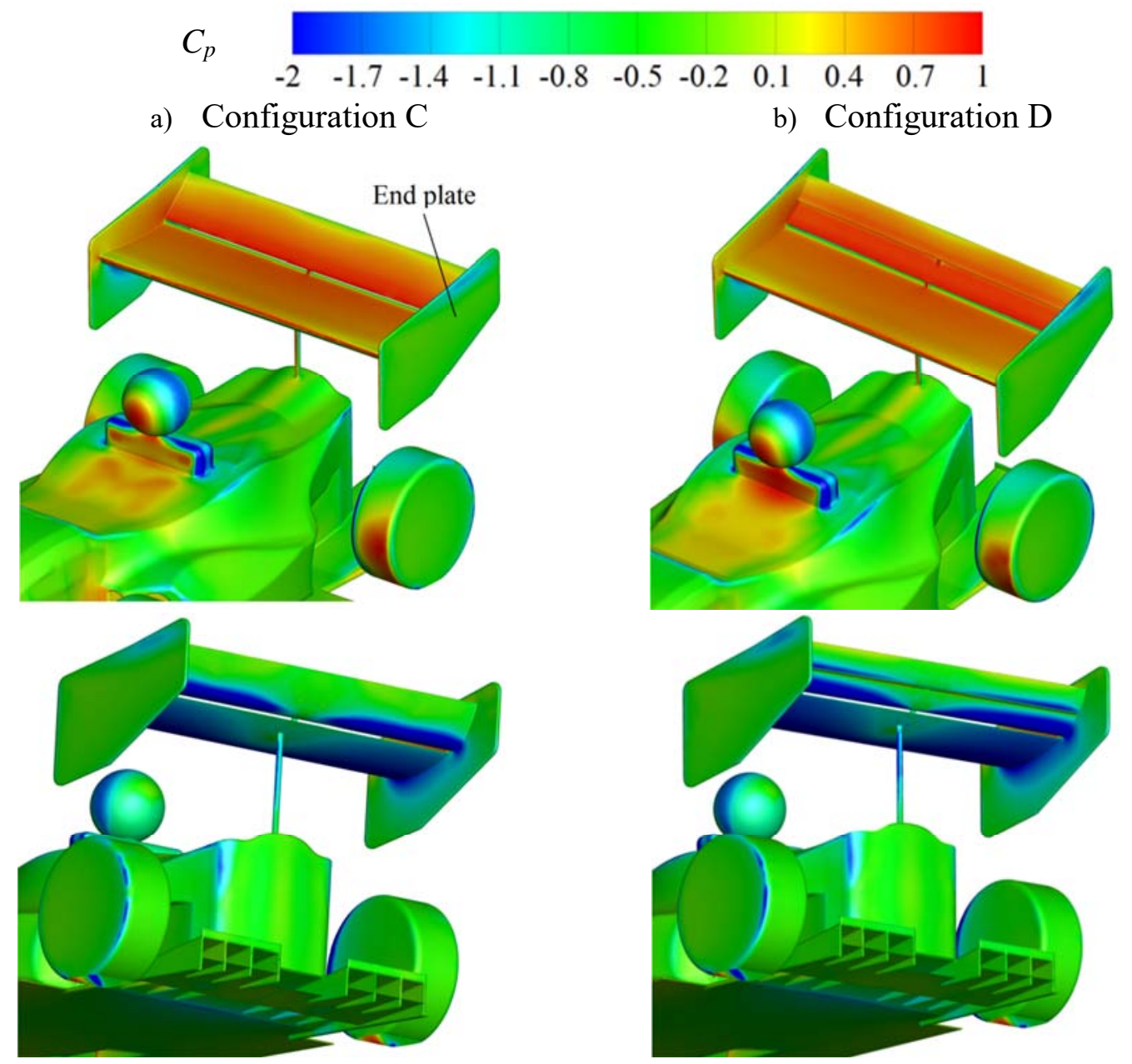

Fig. 13 The $C_{p}$ distribution over the rear part of the car in configurations $C$ and D 
The $C_{p}$ values on the top surface of the rear wing elements are positive in both configurations, i.e. $\mathrm{C}$ and $\mathrm{D}$, with slightly higher values in configuration $\mathrm{D}$. This is similar to the front wing case. Negative $C_{p}$ is obtained on the bottom surface of the rear wing, having similar values in both configurations. This contributes to the enhanced downforce, thus improving the cornering ability of the car.

At the end plate surface directly attached to the rear wing, $C_{p}$ is positive in the area above the rear wing while it is negative below the rear wing and gradually increases to zero. This shows that the selected size of the end plates is sufficient for preventing the development of separating vortices at the rear wing, which is in agreement with [1]. This way, the wing-tip vortices develop from the edges of the end plates; hence, their adverse influence on the flow close to the wing is negligible, Fig. 14. As for the front wing, the results indicate that the rear wing in configurations $\mathrm{C}$ and $\mathrm{D}$ performs nearly in the same way with respect to aerodynamic forces and flow characteristics.

a) Configuration $\mathrm{C}$

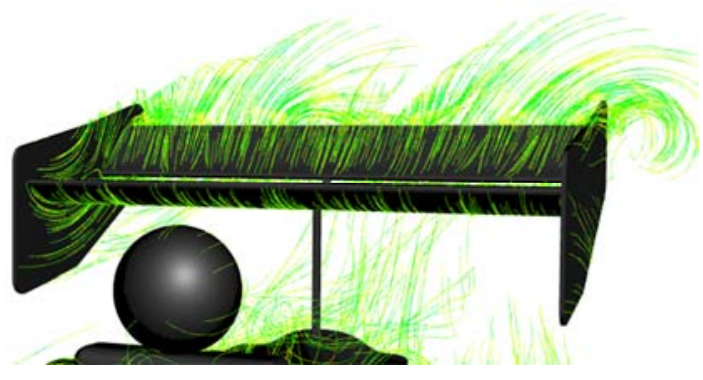

b) Configuration $\mathrm{D}$

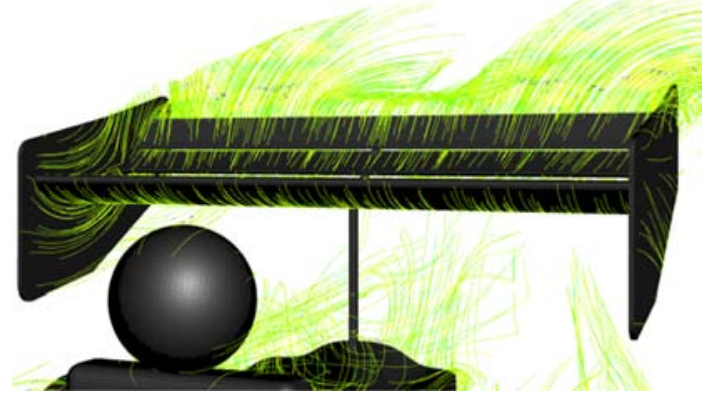

Fig. 14 Flow streamlines close to the rear wing in configurations C and D

While these results indicate that the car dynamics can be improved by implementing the front and rear wings, this is further analysed based on the calculated $C_{D}$ and $C_{L}$ for the entire car, Figs. 15 and 16.

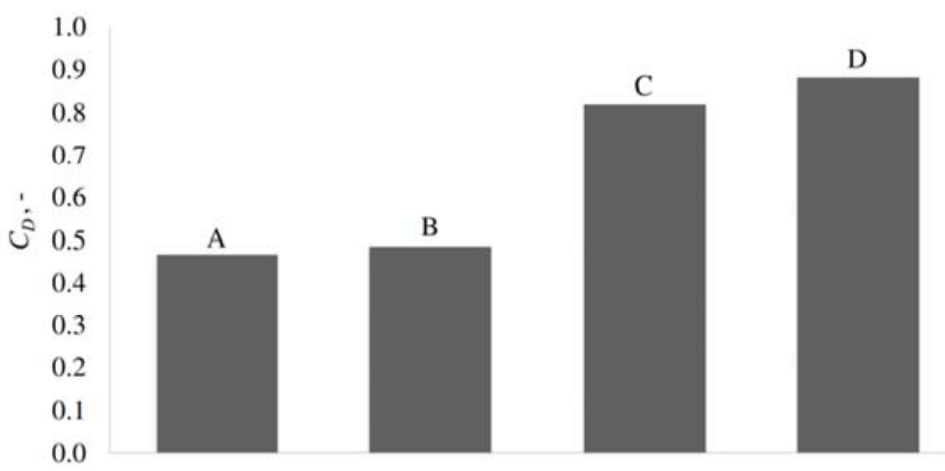

Fig. 15 Calculated $C_{D}$ for configurations $\mathrm{A}, \mathrm{B}, \mathrm{C}$, and D

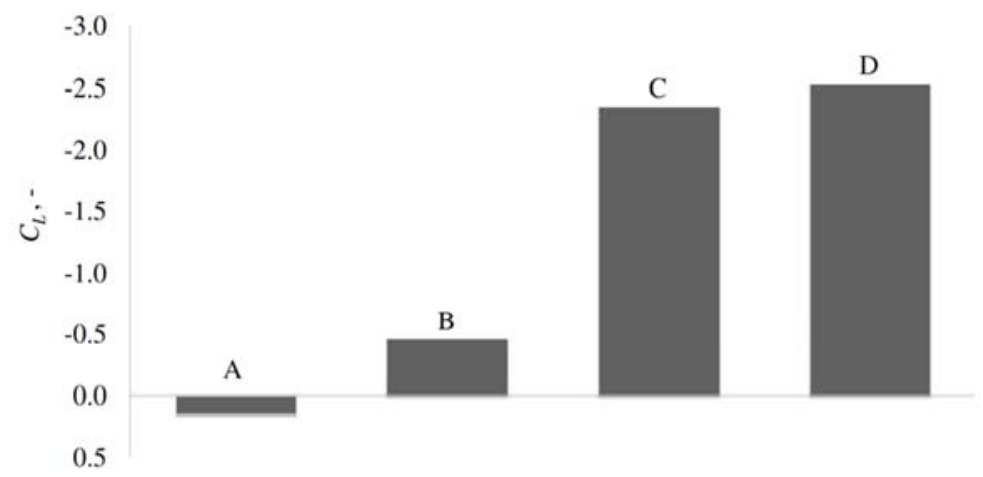

Fig. 16 Calculated $C_{L}$ for configurations A, B, C, and D 
It can be observed that configurations $\mathrm{A}$ and $\mathrm{B}$ yield a similar $C_{D}$ indicating that the rear diffuser does not considerably increase the drag force of the car, while simultaneously producing the favourable downforce that is in agreement with [18], [28]. Configurations $\mathrm{C}$ and $\mathrm{D}$ exhibit an increased $C_{D}$ when compared to configurations $\mathrm{A}$ and $\mathrm{B}$ due to the front and rear wings. This is in good agreement with the results reported in [5], [16]. The maximal $C_{D}$ equal to 0.88 is observed in configuration $\mathrm{D}$, indicating that the $3 \mathrm{EL}$ wing has a higher value of drag force for the same overall chord length and the same wind incidence angle when compared to the $2 \mathrm{EL}$ wing. However, this undesirable increase in $C_{D}$ in configurations $\mathrm{C}$ and $\mathrm{D}$, in comparison with configurations $\mathrm{A}$ and $\mathrm{B}$, is not as significant as a favourable increase in the downforce.

Configuration A (the car with a flat underbody and without the wings) yields a positive $C_{L}$ equal to 0.15 , indicating an adverse upforce in this configuration, while a favourable downforce (negative $C_{L}$ ) is recorded in configurations $\mathrm{B}, \mathrm{C}$, and $\mathrm{D}$. Therefore, higher negative values of $C_{L}$ (stronger downforce) can be observed in configurations $\mathrm{C}$ and $\mathrm{D}$ in comparison with configuration $\mathrm{B}$, indicating a favourable influence of the wings on the overall downforce. The maximal negative value of $C_{L}$ equal to -2.53 is obtained in configuration $\mathrm{D}$, thus indicating that the $3 \mathrm{EL}$ wing is capable of generating a stronger downforce than it is the case with the 2EL wing.

In addition, the $L / D$ ratio is analysed in order to generally quantify the performance of the tested devices and their influence on the race car aerodynamics, Fig. 17. It is considered that the car aerodynamics is better in configurations with higher negative values of $L / D$.

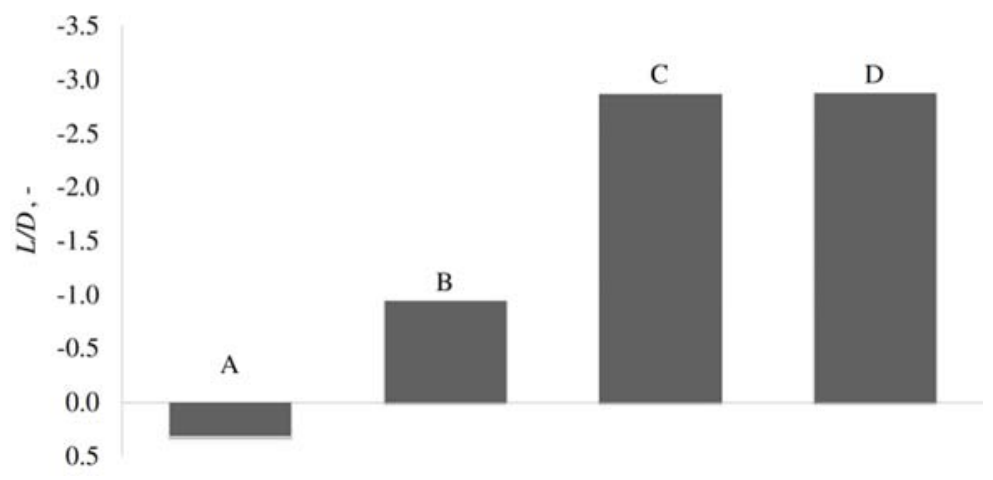

Fig. 17 Calculated $L / D$ for configurations A, B, C, and D

The highest negative $L / D$ values equal to -2.87 are obtained in configurations $\mathrm{C}$ and $\mathrm{D}$, indicating that they perform equally and better in comparison with configurations $\mathrm{A}$ and $\mathrm{B}$. Since the volume of the 3EL wing is smaller than that of the 2EL wing, which results in a decreased weight of the wing, the $3 \mathrm{EL}$ wing is considered to be a more suitable configuration for this type of car. Moreover, in practical motorsport applications, the devices that create a stronger downforce are usually preferred even though they produce a slightly stronger drag force.

The streamlines in configuration D that are obtained at the bottom surface of the rear wing in field experiments are compared with the computational results, Fig. 18. 
a) Computational simulation

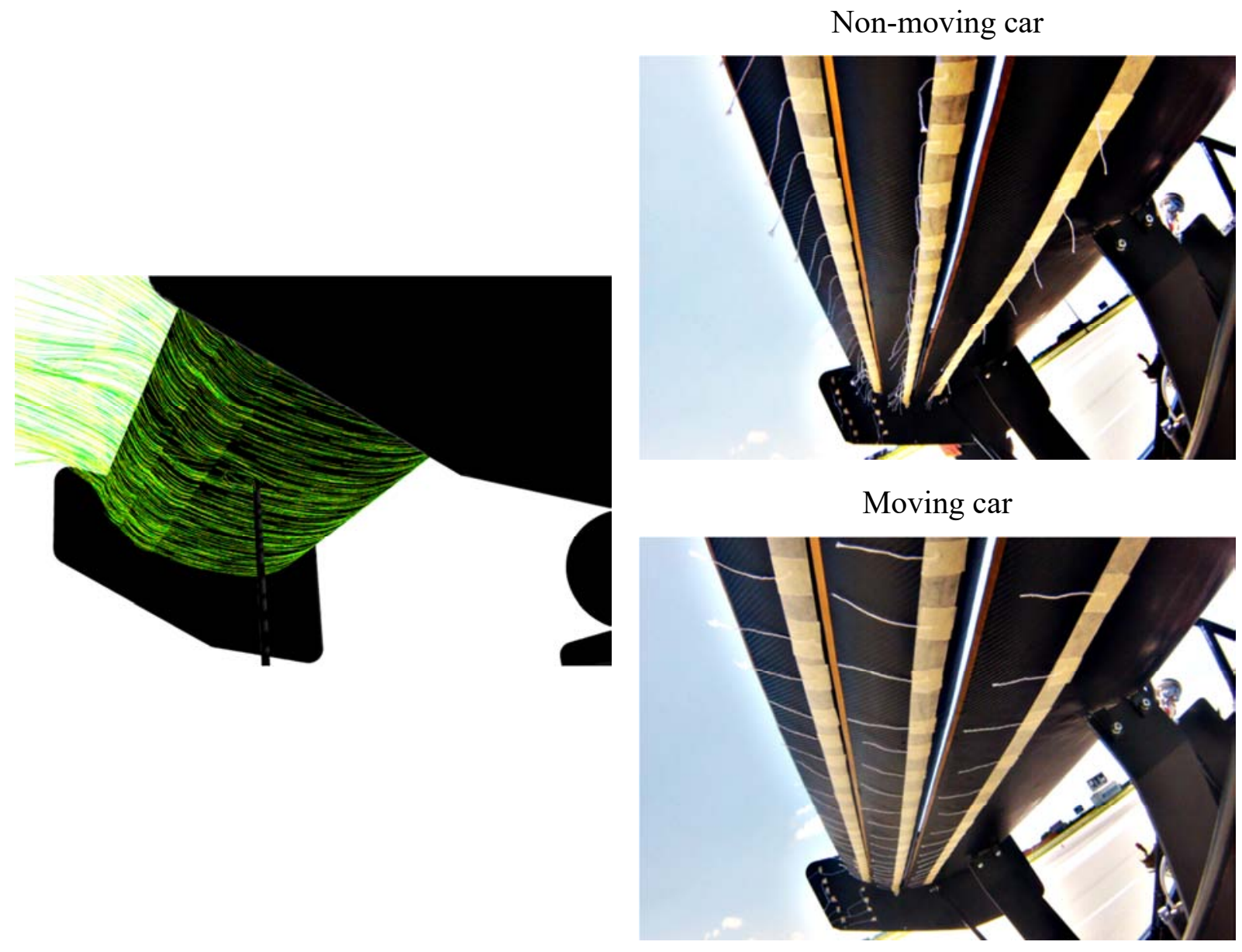

b) Field experiments

Non-moving car

Fig. 18 Streamlines at the bottom surface of the rear wing, a) computational simulation,

b) field experiments; the flow is from the right to the left

Results of both the computational simulation and the field experiment show that the flow separation on the bottom surface of the 3EL rear wing is not present as the streamlines remain attached to the bottom surface of the rear wing elements. However, more field experiments are needed to determine the aerodynamic loads, skin friction and pressure distribution on the car surface to further validate the developed computational approach.

\section{Conclusions}

Influence of the race car underbody, front and rear wings on aerodynamic forces is studied using computational simulations and field experiments. The simulations are performed assuming the steady viscous flow and using the Reynolds-averaged-Navier-Stokes equations along with the standard SST $k-\omega$ turbulence model. In general, the rear diffuser at the trailing edge of the car underbody, the front and rear wings have proved to benefit the race car aerodynamics. In the case of the flat car underbody and the lack of the wings, an adverse upforce is observed, while a favourable downforce is obtained in all configurations with the underbody rear diffuser, and the front and rear wings. The rear diffuser at the trailing edge of the car underbody is generally considered to improve the race car aerodynamics as a favourable downforce is obtained, while there is no considerable undesirable increase in the drag force in comparison with the car with the flat underbody. The front and rear wings produce an enhanced downforce, while the drag force is increased as well. The downforce and the drag force are similar in the case of the wings consisting of two elements to those in the 
case of the wings with three elements. This indicates that for the same overall chord length and wind incidence angle, the number of wing elements is not that important for aerodynamic loads experienced by this type of open-wheel race car with similar front and rear wing layout. This conclusion is based on basic computational simulations performed on two tested wing configurations. Favourable configurations with respect to the lift-to-drag ratio prove to be the ones with the rear diffuser, and the front and rear wings. Since the volume of the threeelement wing is smaller than that of the two-element wing, which results in a decreased weight of the wing, the three-element wing is considered to be a more suitable configuration for this type of car. When the configuration with three-element wings is considered, streamlines in the region of the rear wing are analysed both computationally and experimentally using the tuft flow technique. Good agreement between the computational and limited experimental results regarding the flow characteristics in the region of the rear wing is achieved. However, this would need to be further studied quantitatively in more detail in order to validate the developed computational model. Future work would need to address more complex car geometry, body-aligned computational meshing as well as unsteady flow conditions.

\section{ACKNOWLEDGMENTS}

The authors acknowledge the support of the Croatian Science Foundation.

\section{REFERENCES}

[1] McBeath, S., 2011, Competition Car Aerodynamics, Haynes Publishing, Bristol, Chap. 1, 5.

[2] Katz, J., 2006, "Aerodynamics of Race Cars," Ann. Rev. Fluid Mech., 38, pp. $27-63$. DOI: 10.1146/annurev.fluid.38.050304.092016

[3] Spalart, P. R., 2000, "Strategies for Turbulence Modeling and Simulations," Int. J. Heat Fluid Flow, 21 (3), pp. 252-263. DOI: 10.1016/S0142-727X(00)00007-2

[4] Craig, C., Passmore, M. A., 2014, "Methodology for the Design of the Aerodynamic Package for a Formula SAE Vehicle," SAE Int. J. Passenger Cars - Mech. Systems, 7 (2), pp. 575-585.

[5] Rehnberg, S., Börjesson, L., Svensson, R., Rice, J., 2013, "Race Car Aerodynamics - the Design Process of an Aerodynamic Package for the 2012 Chalmers Formula SAE Car," SAE Technical Papers, 2.

[6] Lu, X., 2015, "Research on the Fow Field Around a Formula SAE car, 14th Symposium on International Automotive Technology," 14th Symposium on International Automotive Technology, SIAT 2015, India.

[7] Patidar, L., Bhamidipati, S. R., 2014, "Parametric Study of Drag Force on Formula Student Electric Race Car Using CFD," Appl. Mech. Materials, 575, pp. 300-305. DOI: 10.4028/www.scientific.net/AMM.575.300

[8] Amromin, E. L., 2013, "Vehicles Drag Reduction with Control of Critical Reynolds Number," ASME J. Fluids Eng., 135 (10). DOI: 10.1115/1.4024803

[9] Axerio-Cilies, J., Iaccarino, G., 2012, "An Aerodynamic Investigation of an Isolated Rotating Formula 1 Wheel Assembly," ASME J. Fluids Eng., 134 (12). DOI: 10.1115/1.4007890

[10] Issakhanian, E., Elkins, C. J., Pong Lo, K., Eaton, J. K., 2010, "An Experimental Study of the Flow Around a Formula One Racing Car Tire," ASME J. Fluids Eng., 132 (7). DOI: 10.1115/1.4001880

[11] Diasinos, S. and Gatto, A., 2008, "Experimental Investigation into Wing Span and Angle-of-Attack Effects on Sub-scale Race Car Wing/Wheel Interaction Aerodynamics," Exp Fluids, 45, pp. 537-546. DOI: $10.1007 / \mathrm{s} 00348-008-0499-\mathrm{z}$

[12] van den Berg, M. A., Zhang, X., 2009, "The Aerodynamic Interaction Between an Inverted Wing and a Rotating Wheel," ASME J. Fluids Eng., 131 (10). DOI: 10.1115/1.3215942

[13] Mahon, S., Zhang, X., 2004, "Computational Analysis of Pressure and Wake Characteristics of an Aerofoil in Ground Effect," ASME J. Fluids Eng., 127 (2), pp. 290-298. DOI: 10.1115/1.1891152

[14] Kuya, Y., Takeda, K., Zhang, X., 2010, "Computational Investigation of a Race Car Wing with Vortex Generators in Ground Effect," ASME J. Fluids Eng., 132 (2). DOI: 10.1115/1.4000741

[15] Katz, J., Largman, R., 1989, "Experimental Study of the Aerodynamic Interaction Between an EnclosedWheel Racing-Car and its Rear Wing," ASME J. Fluids Eng., 111 (2), pp. 154-159.

DOI: $10.1115 / 1.3243616$ 
[16] Chieh-Hsiung, T., Lung-Ming, F., Chang-Hsien, T., Yen-Loung, H., Jik-Chang, L., 2009, "Computational Aero-acoustic Analysis of a Passenger Car with Rear Spoiler," Appl. Math. Modell. 33, pp. 3661-3673. DOI: 10.1016/j.apm.2008.12.004

[17] Norwazan, A. R., Khalid, A. J, Zulkiffli, A. K, Nadia, O., Fuad, M. N., 2012, "Experimental and Numerical Analysis of Lift and Drag Force of Sedan Car Spoiler," Appl. Mech. Materials, 165, pp. 43-47. DOI: 10.4028/www.scientific.net/AMM.165.43

[18] Hu, X., Zhang, R., Ye, Y., Yan, X., Zhao, Z., 2011, "Influence of Different Diffuser Angle on Sedan's Aerodynamic Characteristics," Physics Procedia, 22, pp. 239-245. DOI: 10.1016/j.phpro.2011.11.038

[19] Kang, S. O., Jun, S. O., Park, H. I., Song, K. S., Kee, J. D., Kim, K. H., Lee, D. H., 2012, "Actively Translating a Rear Diffuser Device for the Aerodynamic Drag Reduction of a Passenger Car," Int. J. Automotive Tech., 13, pp. 583-592. DOI: 10.1007/s12239-012-0056-x

[20] West, G. S., Apelt, C. J., 1982, "The Effects of the Tunnel Blockage and Aspect Ratio on the Mean Flow Past a Circular Cylinder with Reynolds Numbers Between 104 and 105," J Fluid Mech., 114, pp. 361-377. DOI: $10.1017 / \mathrm{S} 0022112082000202$

[21] Duan, R., Liu, W., Xu, L., Huang, Y., Shen, X., Lin, C.H., Liu, J., Chen, Q., Sasanapuri, B., 2015, "Mesh type and number for CFD simulations of air distribution in ana aircraft cabin," Num. Heat Trans., Part B: Fundamentals, 67 (6), 489-506. DOI: 10.1080/10407790.2014.985991

[22] Biswas, R., Strawn, R.C., 1998, "Tetrahedral and hexahedral mesh adaptation for CFD problems," App. Num. Math, 26 (1-2), 135-151. DOI: 10.1016/S0168-9274(97)00092-5

[23] Salim, S. M., Cheah, S. C., 2009, "Wall y+ strategy for dealing with wall-bounded turbulent flows," Proc. International MultiConference of Engineers and Computer Scientists Vol II, IMECS 2009, Hong Kong.

[24] Elofsson, P., Bannister, M., 2002, "Drag Reduction Mechanisms due to Moving Ground and Wheel Rotation in Passenger Cars," SAE Paper No. 2002-01-0531.

[25] Menter, F. R., 1994, "Two-equation Eddy-viscosity Turbulence Models for Engineering Applications," AIAA J., 32 (8). DOI: 10.2514/3.12149

[26] Ferziger, J. H., Perić, M., 2002, Computational methods for fluids dynamics, Springer - Verlag, Berlin. DOI: $10.1007 / 978-3-642-56026-2$

[27] Zhang, X., Toet, W., Zerihan J., 2006, "Ground Effect Aerodynamics of Race Cars, ASME Appl. Mech. Rev.," 59 (1-6), pp. 33-48. DOI: 10.1115/1.2110263

[28] Kang, N., Yang, Y., 2014, "Simulation and Analysis of Formula Racing Car's Diffuser Based on CFD Technology," Appl. Mech. Materials, 685, pp. 191-194. DOI: 10.4028/www.scientific.net/AMM.685.191

$\begin{array}{ccl}\text { Submitted: } & 01.02 .2016 & \text { Andrija Buljac } \\ & & \text { Hrvoje Kozmar } \\ \text { Accepted: } & 10.5 .2016 & \text { Ivo Džijan } \\ & & \text { University of Zagreb } \\ & & \text { Faculty of Mechanical Engineering and } \\ & \text { Naval Architecture } \\ & \text { Ivana Lučića 5 } \\ & 10000 \text { Zagreb, Croatia }\end{array}$

